\title{
Inter-organizational design for sustainable transition in agri-food systems: the case of the Paris-Saclay territory
}

\author{
Chloé Le Bail ${ }^{1}$ and Marianne Cerf ${ }^{2}$ \\ ${ }^{1}$ Université Paris-Saclay, CNRS, LISN, UMR 9015, 91400, Orsay, France \\ ${ }^{2}$ Université Paris-Saclay, INRAE, AgroParisTech, UMR SAD-APT, 75005, Paris, France \\ chloe.le-baileuniversite-paris-saclay.fr
}

\begin{abstract}
To reach their desirable vision of what actors mean by sustainable agri-food systems, transition processes take place in which the work activities evolve. The present paper investigates such an evolution through the conceptual framework of organizational design in ergonomics. It aims to understand how evolves the work of actors involved in the transition towards more "localized" production, distribution and consumption of food. We propose to consider the sustainability transition of agri-food systems as an inter-organizational design process, a process by which people redesign rules that guide coordination between organizations. We approach local food systems at the territorial scale to grasp the news forms of coordination in their cultural, spatial, economic, technical, political and ecological context. We consider the inter-organizational design process as the meso-level of actions, which articulates with the micro-level (work activities) as well as the macro-level (public policies, norms in food consumption). The paper presents the case of the association $\mathrm{C}$, which manages catering for a public organization in the Paris-Saclay Plateau. We investigate the ecosystem of actors of the association $\mathrm{C}$, as well as the way by which the catering manager develops and redesigns coordination at the various levels of actions.
\end{abstract}

Keywords: Food systems, Sustainability transition, Organizational design, Work activities, Multi-level of actions

\section{Introduction}

For several years, health and economic crises have highlighted the vulnerability of globalized agricultural value chains. It is now well recognized that agri-food systems need significant transformation of the existing standardized food regime to become more sustainable [1]. One approach on the definition of sustainable agri-food system is: a set of practices, from the production to the consumption of food products, economically viable, socially sustainable and ecologically responsible [2]. In this definition, sustainable food is not only about organic food. It concerns the quality of the food, the number of intermediaries and the geographic proximity as well [3]. The main objectives are to guarantee self-sufficiency and food security, to support the local economy, and to reduce GES emissions [4]. 
Sustainable agri-food systems require sustainability transition, namely is a process of change from one sociotechnical system to another [5]. Over the last two decades, the field of Sustainability Transitions Studies has explored processes of innovation in agri-food systems towards more sustainability [2]. Many scholars analyze bottom-up initiatives, namely innovations developed by some actors for their own benefit. They identify local food systems as social innovations, which encourage fair prices, solidarity, democracy and participatory processes between different actors, especially farmers and consumers [6]. Here, Social Innovation refers to a set of innovative activities and services that are motivated by the goal of meeting a social need [7]. It generates new forms of collaboration between people and promotes community values such as equity and mutual aid.

However, in local food systems, work activities might be quite different from what they ought to be in globalized agricultural value chains. The aim of this paper is to understand how evolves the work of actors involved in the transition towards more "localized" production, distribution and consumption of food. We propose to consider the sustainability transition of agri-food systems as an inter-organizational design process, namely a process by which people redesign rules that guide coordination between organizations. We approach local food systems at the territorial scale to grasp the news forms of coordination in their cultural, spatial, economic, technical, political and ecological context. The objective is to understand local food systems as anchored in particular territories, which implies the existence of social networks at this scale (local authorities, distribution platforms), institutional regulations (for example, Territorial Food Program) and specific forms of sharing knowledge, knowhow and traditions [8].

Therefore, we grasp the concept of territory as the result of the combination of geographical, economic, cultural and socio-political factors and try to capture its dynamics through the lens of a transition process to address a societal function (here, food). We see the territory as a complex and situated system, which takes shape according to human interactions, interactions between individuals and organizations, and interactions between humans and the natural environment [9]. It implies to consider different scales of actions, and to understand how work activities evolve within and throughout these various scales. We consider the inter-organizational design process as the mesolevel of actions, which articulates with the micro-level (work activities) as well as the macro-level (public policies, norms and conventions in food consumption). We question how, in such a design process, the various actors deal with their interdependencies and debate about their way to define what local and more generally sustainable food means. How evolves inter-organizational coordination to produce and consume sustainable food and to build a territorialized agri-food system? How does it change the work of the actors involved? 


\section{$2 \quad$ Method}

\subsection{Context}

We have conducted a case study in the Paris-Saclay Plateau located in the south of Paris. It is a peri-urban area, which is favorable to the emergence of local food systems. Paris-Saclay Plateau is close to a dense urban area where prosperous agricultural activities remain, despite huge construction sites for the installation of both private companies and public infrastructure (universities and research centers). Local stakeholders try to preserve agricultural and natural spaces to develop the well-being of people and an area is identified as a protected agricultural land reserve (ZPNAF). The past few years, local initiatives (i.e., short food-supply chains) have emerged to help the connection between local consumption and local production [10].

More precisely, we have focused on the delivery of local products in the canteens of companies and universities based on the Paris-Saclay Plateau. In France, the Egalim law was passed in 2018, with the objective to promote a healthy, safe, sustainable diet for all by introduction in school and university canteens of $50 \%$ quality-labeled or organic products starting on January 1st 2022. Canteens are encouraged to source products obtained via Territorial Food Program even though these products are not counted in the $50 \%$ of sustainable products. In this context, we have explored how actors that have key roles in inter-organizational coordination (local producers, canteen managers, NGOs that aim at developing sustainable food practices in the area) articulate their actions to develop the local food system.

\subsection{Data collection}

Data collection was carried out between October 2019 and May 2020 by researchers in Ergonomics and Management Science. Twelve interviews were conducted with:

- Experts, to understand the functioning of company canteens in France, and the changes related to the introduction of sustainable products, including local products (three interviews);

- Managers in charge of sustainable development issues in companies, in the case where companies do not have canteens (two interviews);

- Catering managers, for companies which have canteens (three interviews);

- Producers and processors of local products included in the menus of the canteens where we interviewed the managers (three interviews);

- The most important local NGO, which works with public authorities on the definition of the Territorial Food Program in Paris-Saclay Plateau (one interview).

Furthermore, we collected some documents that help actors to coordinate their work (e.g., contracts, invoices). 


\subsection{Data analysis}

Data analysis was based on the framework of organizational design in ergonomics, where organizational change is seen as a collective design process distributed in time and space. In such a perspective, the operator is considered as the "designer" of his own work, and as the designer of its own work organization [11; 12]. Collective work refers to the way in which operators cooperate in a more or less effective manner to achieve a common goal. It implies processes of task allocation, coordination of activities and "re-design" of rules to articulate individual objectives, as well as to guarantee a "good" job that satisfies all stakeholders [13].

Firstly, we have identified the ecosystem of actors of the managers and the producers interviewed, and who are involved in the development of local food consumption in the canteens. Secondly, we have focused on how these managers and producers articulate three types of coordination to develop local food consumption: 1) a coordination within organizations at the micro-level of actions (work activities); 2) a coordination between organizations at the meso-level of actions (inter-organizational coordination); and 3) a coordination which aims at changing some norms and conventions in food consumption at the macro-level of actions. The multi-level perspective refers to the complexity of actors within the ecosystem in terms of governance (i.e., how entities are directed and controlled, how and by who rules are decided). Therefore, such a perspective refers to how actors can change the structure and the rules of coordination that guide the interactions between them. We have considered that an upper level is more complex and more stable than a lower one.

\section{$3 \quad$ Results}

We present the ecosystem of actors of the association $\mathrm{C}$, which manages catering for a public organization in the Paris-Saclay Plateau. The association $\mathrm{C}$ manages three restaurants. Each one has its own kitchen and employs between 16 and 20 employees distributed as follows: a chef, cooks, a storekeeper, catering staff. The three restaurants are open only for lunch, Monday to Friday, and approximately 230 days per year. Each year, the catering manager creates a provisional financial plan that must be approved by the direction. The plan includes food needs, equipment needs, cleaning needs and labor needs. The manager is also in charge of the respect of hygiene norms, nutrition and provision of meals. He chooses suppliers according to which possibilities the financial plan offers to him. For example, sustainable products are generally more expensive than other products, so the manager adapts the number and the type of sustainable products he orders to cope with the financial conditions.

The figure 1 illustrates the ecosystem of actors of the association $\mathrm{C}$ and the three types of coordination: 1) coordination of activities within restaurants (micro-level); 2) inter-organizational coordination, which concerns restaurants and local producers (meso-level); and 3) coordination which takes place on a more macroscopic level and which concerns institutions, public policies and catering national societies. 


\subsection{Variability of coordination with producers}

Relationships between the association $\mathrm{C}$ and local producers-processors are diverse. Such a diversity shows that the catering manager wishes to adapt the functioning of the association $\mathrm{C}$ to the characteristics and the needs of the various farms. The result highlight three categories of relationship (see figure 1):

- Regular order: the producer delivers always the same quantity in a regular and on-going manner (e.g., every day). It is the case of the producer 1 who delivers systematically its chickens every month, and the producer 2 who delivers regularly its yoghurts. These two producers are located in the Paris-Saclay Plateau.

- Irregular order: the producer does not deliver the same quantity each time and/or the delivery days are not the same over time. It is the case of the producer 3 who delivers various quantity of bread according to the period of the year. Indeed, the catering manager has accepted to buy more bread each week before schools holiday to support the producer in the loss of income during holidays. The producer 3 is located in the Paris-Saclay Plateau.

- Exceptional order: the catering manager helps a producer-processor who needs to find urgently a market for its products. It is the case of the producer 2 who sometimes has a surplus of vegetables and the catering manager buys the surplus to avoid waste. It is also the case for producers who are not usually in the ecosystem of the association $\mathrm{C}$, such as the producer 4 who is located in Brittany. Once, the manager accepted to help the producer who had 500 chickens to sell urgently. He wanted to help the producer to rebuild up its cash flow.

The three categories of relationship highlight that the catering manager wants to support local food consumption, in the Paris-Saclay Plateau, as well as in the "best possible proximity". The manager wants to support French agriculture as a whole. But the expansion of the criterion of "locality" is also due to the absence of some products in the Paris-Saclay Plateau. In other words, the area does not offer enough food resources to meet the requirements of the restaurants.

\subsection{Influence at micro-level}

The actions that the catering manager develops at meso-level of actions (coordination with producers-processors) affect the micro-level of actions (work within the canteen). For example, the purchase of a surplus of vegetables "in the last minute" requires to change the menus and to adapt other orders. Normally, the process by which the menus are elaborated and then ordered is as follow (see figure 1):

1) Menus are created during a committee which involves the catering manager, the administrative staff, the direction, a dietician, cooks, consumer representatives. The committee approves the menus for a period of twenty days, which corresponds to the national recommendations for respecting a dietary balance.

2) The restaurants order the food they need at least one week before. This time of one week is necessary for the buyer of the association to prepare the orders. The buyer centralizes the requests and places orders with suppliers. 
3) The products are delivered directly to the restaurants according to a delivery schedule established with the supplier.

To help a producer or to support local production, the catering manager does not hesitate to change the rules (of elaboration of menus) that he has himself designed.

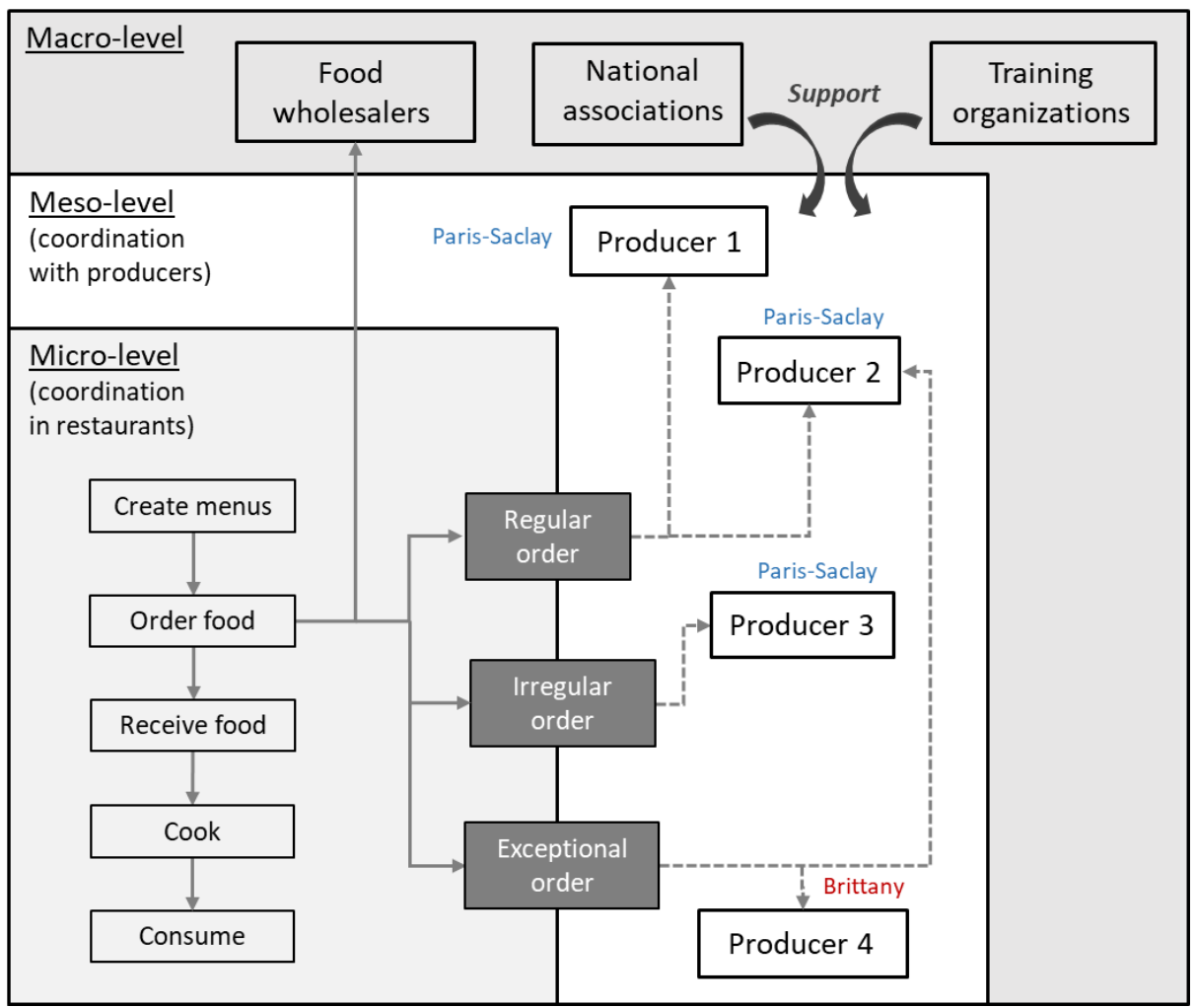

Fig. 1. Ecosystem of actors of the association C.

\subsection{Relation with macro-level}

At the macro-level of actions, the catering manager coordinates its actions with dominating food wholesalers that help him to find products less expensive, as close as possible to the restaurants. As well, he coordinates its actions with catering national societies to obtain a certain degree of latitude. For example, the association $\mathrm{C}$ is very engaged in a national association for catering professionals. During the elaboration of the Egalim law, the catering manager of the association $\mathrm{C}$ has contributed to increase the limitation from which suppliers are put into competition on the basis of a call for tenders. The limitation has been increased from 25,000 euros to 40,000 euros per year, excluding taxes. Such an augmentation is favorable for "little" suppliers such as local producers for which competition is hard to manage. 
In the same idea, the association $\mathrm{C}$ works with private national training organizations to develop the skills of employees. Indeed, collective catering involves specific skills and know-how to re-introduce fresh and local products in cooking practices.

\section{Discussion}

The transition of agri-food systems to provide more sustainable food to employeesconsumers in the Paris-Saclay area implies an organizational work at both micro and meso-levels of actions. Furthermore, it implies that the organizational work articulates with the macro-level of actions.

To produce and consume sustainable, local food, and to build a territorialized agrifood system, actors must redesign "during the use" the inter-organizational coordination between restaurants and producers. Such a redesign is constraints by the macrolevel of actions (the public policies, the norms and convention), by the geographical and cultural dimensions of the territory (e.g., what resources are existing, how people consider this resources), and by the possibilities of transformation and evolution of work situations (i.e., do the transformations respect health and safety?).

Implications for ergonomics intervention are twofold. Firstly, it implies to identify at least two processes of coordination and their reconfigurations, one inside the organizations, the other between the organizations. Secondly, it implies to identify which criteria are in stake in the reconfigurations (e.g., sustainability, locality, territoriality), and their signification from the point of view of the actors involved in interorganizational design process.

\section{References}

1. Meynard, J. M., Jeuffroy, M. H., Le Bail, M., Lefèvre, A., Magrini, M. B., Michon, C.: Designing coupled innovations for the sustainability transition of agrifood systems. Agricultural Systems 157, 330-339 (2017).

2. Gaitán-Cremaschi, D., Klerkx, L., Duncan, J., Trienekens, J. H., Huenchuleo, C., Dogliotti, S., Contesse, M.E., Rossing, W. A.: Characterizing diversity of food systems in view of sustainability transitions. A review. Agronomy for Sustainable Development 39(1), (2019).

3. Renting, H., Marsden, T. K., Banks, J.: Understanding alternative food networks: exploring the role of short food supply chains in rural development. Environment and planning A 35(3), 393-411 (2003).

4. FAO. Sustainable healthy diets - Guiding principles. Rome (2019).

5. Rip, A., Kemp, R.: Technological change. Human choice and climate change, 2(2), 327399 (1998).

6. Chiffoleau, Y., Loconto, A. M.:. Social Innovation in Agriculture and Food. International Journal of the Sociology of Agriculture and Food, 24(3), 306-317 (2018).

7. Mulgan, G.: Social Innovation: How Societies Find the Power to Change. Bristol University Press, Bristol, UK (2019).

8. Lamine, C., Garçon, L., Brunori, G.: Territorial agrifood systems: A Franco-Italian contribution to the debates over alternative food networks in rural areas. Journal of Rural Studies 68, 159-170 (2019). 
9. Moine, A.: Le territoire comme un système complexe : un concept opératoire pour l'aménagement et la géographie. L'Espace géographique 35(2), 115-132 (2006).

10. Tedesco, C., Petit, C., Billen, G., Garnier, J., Personne, E.: Potential for recoupling production and consumption in peri-urban territories: The case-study of the Saclay plateau near Paris, France. Food Policy 69, 35-45 (2017).

11. Coutarel, F., Petit, J.: Le réseau social dans l'intervention ergonomique : Enjeux pour la conception organisationnelle. Management et Avenir 7(27), 135-151 (2009).

12. Arnoud, J., Falzon, P.: Changement organisationnel et reconception de l'organisation : des ressources aux capabilités. Activités 10(2), (2013).

13. Caroly, S., Barcellini, F.: The development of collective activity. Constructive ergonomics. In: P., Falzon (eds.) Constructive ergonomics, pp. 19-32. CRC Press, Boca Raton (2014). 